\title{
Influence of Long Term Fertilization With NPK on Wheat Production and Chemical Characteristics of Typical Chernozem From Valu lui Traian
}

\author{
Mihail DUMITRU ${ }^{1 *}$, Naliana LUPAȘCU², Nicoleta MĂRIN ${ }^{1}$ \\ ${ }^{1}$ National Research and Development Institute for Soil Science, Agro-Chemistry and Environment - \\ ICPA Bucharest, 61 Marasti Blvd, District 1, Bucharest, Romania. \\ ${ }^{2}$ National Research and Development Institute for Marine Geology and Geoecology, \\ 304 Mamaia Blvd, Constanța, Romania \\ *corresponding author e-mail: mihail.dumitru@icpa.ro
}

Bulletin UASVM series Agriculture 76(1) / 2019

Print ISSN 1843-5246; Electronic ISSN 1843-5386

DOI:10.15835/buasvmcn-agr: 2019.0009

\begin{abstract}
To determine the evolution soil fertility as a result of NPK fertilization, are presented experimental results from a long-term experience after 44 years of fertilization. The experimental field is located on the chernozem soil type, the plant of culture was wheat. Nitrogen and phosphorus doses that were applied had 2 graduations. We tracked the influence of fertilizers on the production and content of nitrogen, phosphorus, potassium, humus, $\mathrm{pH}$ and heavy metals: $\mathrm{Cu}, \mathrm{Cd}, \mathrm{Pb}$ and $\mathrm{Zn}$ from the soil after harvesting. The highest yield (4288 $\mathrm{kg} / \mathrm{ha}$ ) was obtained in fertilized variants with $\mathrm{N}_{100} \mathrm{~K}_{150}$, variants where the production level increased by $216 \%$ compared to the unfertilized soil (1987 kg / ha); Fertilization with $100 \mathrm{~kg} /$ ha of phosphorus alone or with 50-150 kg / ha of potassium and fertilization with $\mathrm{N}_{100} \mathrm{P}_{100}$ along with doses of 50-150 kg / ha of potassium have led to very significant increases in the level of the mobile phosphorus in soil (from $34 \mathrm{mg} / \mathrm{kg}$ in unfertilized soil to $178 \mathrm{mg} /$ kg in variant fertilized with $\mathrm{N}_{100} \mathrm{P}_{100} \mathrm{~kg} / \mathrm{ha}$ ), the potassium content of the soil increased very significantly with the increase of the applied potassium dose.
\end{abstract}

Keywords: nfluence of Long Term Fertilization with NPK, nitrogen, phosphorus, potassium, heavy metals

\section{Introduction}

For plant nutrition, the key to sustainable farming is the nutrient circuit. In the agricultural system, the main loss in this circuit is the export of nutrients through the harvested production. These losses are minimized if the crop feeds animals and only the main animal products leave the farm, and the secondary ones return to the soil-plant circuit. Researches have shown that chemical fertilizers are the main source of compensation for losses from agricultural ecosystems, while organic livestock manure is used as soil amendment to maintain an acceptable level of organic matter (Ciobanu, 1999).

Chemical fertilizers used in accordance with soil fertility, ecological conditions and crop requirements for nutrients do not have any negative effects on the environment (Dorneanu, 2001). The amount of organic fertilizer was and is insufficient (in 1985 the total amount of manure provided $40 \mathrm{~kg} \mathrm{~N}, 10 \mathrm{~kg} P$ and $23 \mathrm{~kg} \mathrm{~K}$ for every hectare of arable land (Răuţă and Dumitru, 1986) and in 2012 the values decreased 4 times due to the drastic reduction in the number of animals to fertilize the entire area, it is necessary that the consumption of chemical fertilizers increases continuously. At the time of the longterm experiences organization, ensuring the NPK requirement was an issue. Values of $\mathrm{K}$ were introduced in Valu's Traian soil because the level of soil supply in this element was low and could lead to a reduction in production and the quality of it. 


\section{Materials and Methods}

The experience has tracked the influence of mineral fertilization with nitrogen, phosphorus and potassium on wheat production and chemical soil characteristics. The fertilization protocole involves the administration of $\mathrm{N}_{100} \mathrm{~K}_{150}$, fertilizer in ransomised blocks and three repetitions.

Production data and soil samples refer to the $44^{\text {th }}$ year of uninterrupted operation of the experience. The soil samples were sampled on a depth of 0-20 cm. For the chemical characterization were used the following methods:

- SR ISO 11464: 1998 Soil conditioning, drying, milling and preparation for analysis;

- STAS 7184 / 21-82. - organic matter (humus): volumetric determined by wet method after Walkley Black modified by Gogoașa;

- SR ISO 11261: 2000 - total nitrogen (N\%): Kjeldahl method, dissolution with $\mathrm{H}_{2} \mathrm{SO}_{4}$ at $350^{\circ} \mathrm{C}$, potassium sulphate catalyst and copper sulphate;

- Accessible (mobile) phosphorus: Egner-RiehmDomingo method and molybdenum blue colorimetric method, Murphy-Riley method (ascorbic acid reduction);

- Accessible potassium (mobile): Egner-RiehmDomingo extraction and flame photometry.

\section{Results and Discussions}

\section{The influence of with NPK fertilizers upon winter wheat yield}

The data presented in Figure 1 highlight the influence of long-term fertilization (44 years) on the wheat production obtained on the typical chernozem from Valu lui Traian, showing the following:

- Production increased with higher fertilizer doses; The highest yield (4288 kg/ha) was obtained in fertilized variants with $\mathrm{N}_{100} \mathrm{~K}_{150}$, where the production level increased by $216 \%$ compared to the unfertilized soil (1987 kg/ha);

- Potassium fertilization brought a significant boost in production (37\%) by fertilization with $50 \mathrm{~kg} /$ ha K; a distinctly significant production increase $(49 \%)$ at $100 \mathrm{~kg} / \mathrm{ha}$ and a very significant increase in production (153\%) compared to unfertilized variant by application of $150 \mathrm{~kg} /$ ha $\mathrm{K}$; the average on the experimental block, fertilization with potassium yielded a $46 \%$ production increase, or $13.8 \mathrm{~kg}$ of wheat per $\mathrm{kg}$
$\mathrm{K}$ fertilizer; this is a very high raise, due to the low supply of soil with this element;

- The application of $100 \mathrm{~kg} / \mathrm{ha}$ of phosphorus led to a significant growth in production (31\%) compared to unfertilized variant; Application of doses of $50-150 \mathrm{~kg} / \mathrm{ha} \mathrm{K}$ on the basis of 100 $\mathrm{kg} / \mathrm{ha} \mathrm{P}$ resulted in very significant production increases compared to the unfertilized soil; the production benefit provided by $\mathrm{K}_{100}$ on the $\mathrm{P}_{100}$ background were very significant compared to fertilization only with this element, being $41 \%$ for $\mathrm{P}_{100} \mathrm{~K}_{50}$ fertilization, $46 \%$ for fertilization with $\mathrm{P}_{100} \mathrm{~K}_{100}$ and $60 \%$ for fertilization with $\mathrm{P}_{100} \mathrm{~K}_{150}$; On the background of P100 fertilization with potassium was very effective by providing a production increase of $19 \mathrm{~kg}$ of wheat per $\mathrm{kg}$ K fertilizer;

- Fertilization with $\mathrm{N}_{100}$ provided a very significant increase in production (80\%) compared to the non-fertilized control; Fertilization with various doses of $\mathrm{K}$ on a background of $100 \mathrm{~kg} / \mathrm{ha}$ of nitrogen resulted in very significant production plots (208-216\%) compared to the nonfertilized control; production gains provided by $\mathrm{K}$ were statistically significant compared to fertilization with $\mathrm{N}_{100}$ alone; when applying $\mathrm{K}$ on the $\mathrm{N}_{100}$ background, the production increase per kg of K was $9.4 \mathrm{~kg}$, a very high increase if we take into account the high production level;

- Fertilization with $\mathrm{N}_{100} \mathrm{P}_{100}$ provided a very significant plus of production (204\%) compared to the unfertilized witness; on this fertilizer fund with $\mathrm{N}_{100} \mathrm{P}_{100}$, the fertilization with $50 \mathrm{~kg} /$ ha of potassium provided a production increase of $209 \%$, at $100 \mathrm{~kg} / \mathrm{ha} \mathrm{K}$, an increase of $211 \%$ and the application of $150 \mathrm{~kg} / \mathrm{ha} \mathrm{K}$, a $207 \%$; on this fertilization fund with $\mathrm{N}_{100} \mathrm{P}_{100}$ potassium has not yet provided significant production surpluses compared to background fertilization; the increase in wheat production per $\mathrm{kg}$ of $\mathrm{K}$ was only $1.3 \mathrm{~kg} / \mathrm{kg}$;

- Following the production increase on the blocks, compared to the unfertilized version, it can be noticed that by K-only fertilization the average production yield was 35\%, on the background of $\mathrm{P}_{100}$ the average growth was $79 \%$, on the background of the $\mathrm{N}_{100}$ average growth was $103 \%$ and on the background of $\mathrm{N}_{100} \mathrm{P}_{100}$ the average increase was $208 \%$, and the wheat per $\mathrm{kg}$ of $\mathrm{K}$ was $13.8 \mathrm{~kg} / \mathrm{kg}$ in the fertilized block with only $\mathrm{K}, 19 \mathrm{~kg} / \mathrm{kg}$ by applying $\mathrm{K}$ on the 


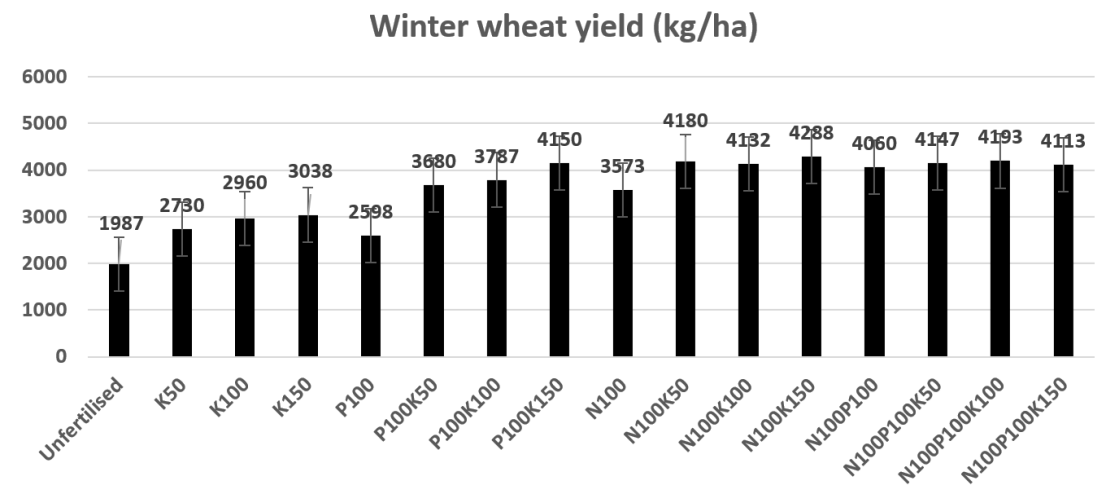

Figure 1. Graphical representation of the influence of long-term mineral fertilization (44 years) with NPK upon wheat yield grown on the typical chernozem from Valu lui Traian

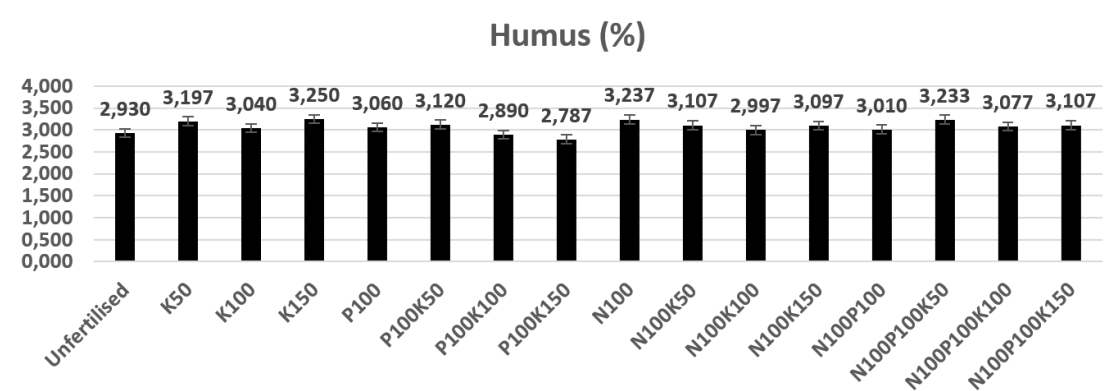

Figure 2. Graphical representation of the influence of long term mineral fertilization (44 years) with NPK on the humus content from the typical chernozem from Valu lui Traian

background of $\mathrm{P}_{100}$, of $9.4 \mathrm{~kg} / \mathrm{kg}$ in the case of applying $\mathrm{K}$ on the background of $\mathrm{N}_{100}$ and of $1.3 \mathrm{~kg} / \mathrm{kg}$ in the case of applying $\mathrm{K}$ on the background of $\mathrm{N}_{100} \mathrm{P}_{100}$.

It can be concluded that potassium fertilization is efficient and obligatory for wheat cultivation on the typical chernozem of Valu lui Traian.

Sala (2011) considered that potassium applied by fertilization should provide the necessary crops for normal nutrition and the expected yield. The dose correlates with the supply of potassium in the soil, the specific consumption of the cultivated plants as well as the other nutrients and the culture conditions.

Considering the potassium regime in the soil, to provide plants with this element on poorly supplied soils, the fertilizer doses will exceed the plant requirement by $50 \%$. Failing to consider potassium deficiency on the grounds that our soils are supplied with this element and the unilateral use of nitrogen and phosphorous fertilizers only results in a cropping cap, since the crop is determined by the element who is at a minimum, in this case potassium (Davidescu and Davidescu, 1979).
2. The influence of fertilization with NPK on chemical characteristics of soil In Figure 2 are presented the data reflecting the influence of long-term fertilization (44 years) on NPK on the humus content of the typical chernozem of Valu Traian. The data do not reveal statistically significant changes in the humus level in the soil. Only a growing trend is observed in plots fertilized with various doses of potassium, NP and NPK. Only in the case of fertilization with $\mathrm{P}_{100} \mathrm{~K}_{100}$ and $\mathrm{P}_{100} \mathrm{~K}_{150}$ a slight decrease in humus content is observed.

The influence of long-term fertilization (44 years) on NPK on the evolution of total nitrogen in soil is shown in Figure 3. The various doses of mineral fertilizers with applied NPK did not lead to statistically significant changes in the total nitrogen content of the typical chernozem Valu lui Traian.

Figure 4 shows the data reflecting the evolution of the content of the mobile chernozem phosphorus in from Valu Traian after 44 years of fertilizer application with NPK.

The data highlight the following:

- Fertilization with $100 \mathrm{~kg} /$ ha of phosphorus alone or together with doses of 50-150 kg/ha of 


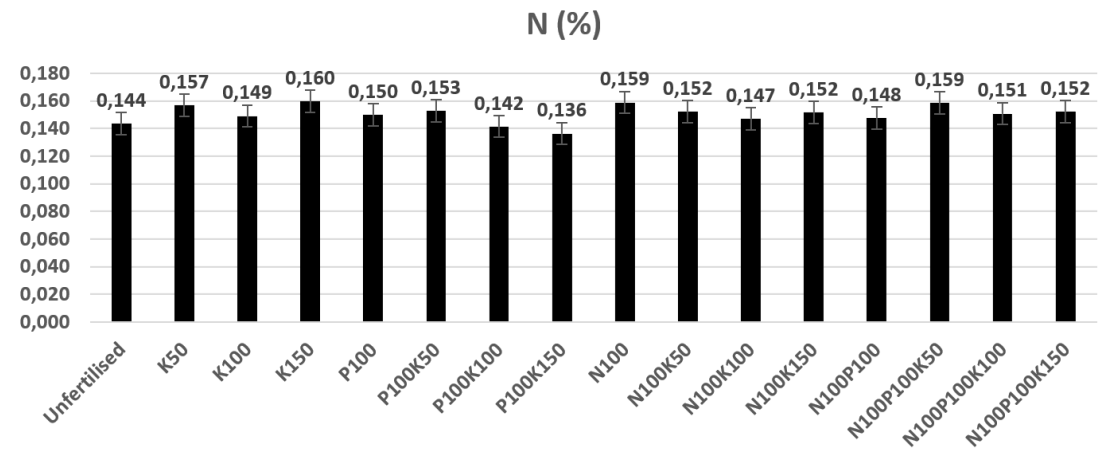

Figure 3. The graphical representation of the influence of long term mineral fertilization (44 years) with NPK on the total content of nitrogen from the typical chernozem from Valu lui Traian

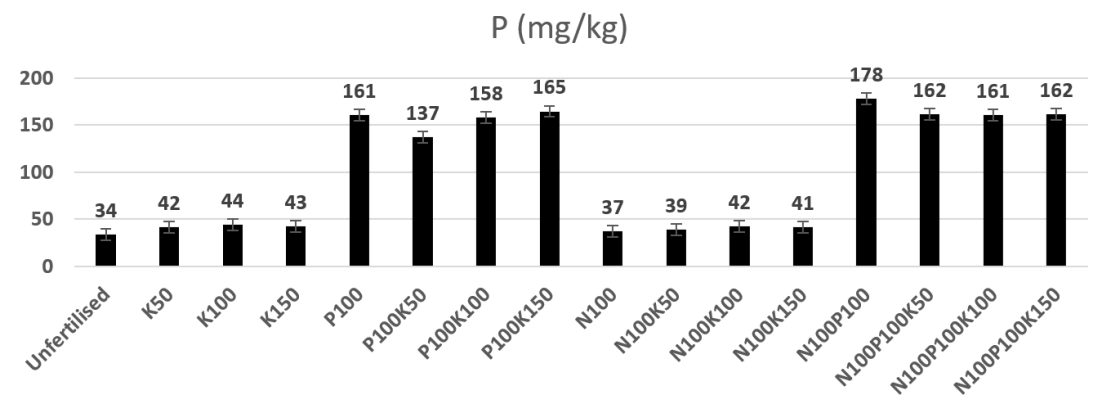

Figure 4. The graphical representation of the influence of long term mineral fertilization (44 years) with NPK on the phosphorus content from the typical chernozem from Valu lui Traian

potassium and $\mathrm{N}_{100} \mathrm{P}_{100}$ fertilization along with $50-150 \mathrm{~kg} / \mathrm{ha}$ of potassium have led to very significant increases in the level of phosphorus in the soil;

- Fertilization with various potassium doses alone or on the background of N100 did not lead to statistically significant changes in soil phosphorus content;

- In all variants fertilized with $100 \mathrm{~kg} / \mathrm{ha} \mathrm{P}$ the level of soil supply in this element has become „very high”.

Borlan and Hera (1984) showed that the application of relatively small doses of watersoluble phosphate fertilizers can substantially alter the phosphorus concentration in the soil solution so that it corresponds to the phosphorus nutrition requirements of plants in the intensification of agriculture.

Borlan et al. (1994) shows that in relation to nitrogen and potassium fertilization alone, the application of stationary phosphorus fertilizers always engages the mobile phosphorus content in a positive evolution, which may be apparent when the $\mathrm{P}_{2} \mathrm{O}_{5}$ dose is lower than the export with harvests and real if the $\mathrm{P}_{2} \mathrm{O}_{5}$ dose embedded in the soil substantially exceeds phosphorus harvest export. It can be seen that the dose of $100 \mathrm{~kg} /$ ha of phosphorus substantially exceeds the consumption of phosphorus by corn crops and thus allows for the increase of soil reserves in this element.

In order to keep the phosphorus content in the solution at a certain level in soils with a high fixation capacity, as is the case with the typical chernozem of Valu Traian, which has carbonates from the surface, it is necessary to supplement the fertilizer with phosphorus. Almost in all soils, phosphorus concentration in the solution increases with increased phosphorus supplementation (Sala, 2011).

Under conditions of application of phosphate fertilizers in small and moderate annual doses, the content of mobile phosphates in the soil layer changes in proportion to the total applied phosphorus dose (Vintilă et al., 1984).

In the case of non-application of phosphatic fertilizers, the content of mobile phosphates is a result of two categories of processes: decline through plant consumption and immobilization, and growth through biochemical mobilization (Borlan and Hera, 1984).

The evolution of the mobile potassium content in the typical chernozem of Valu Traian under the influence of the long-term fertilization (44 years) 


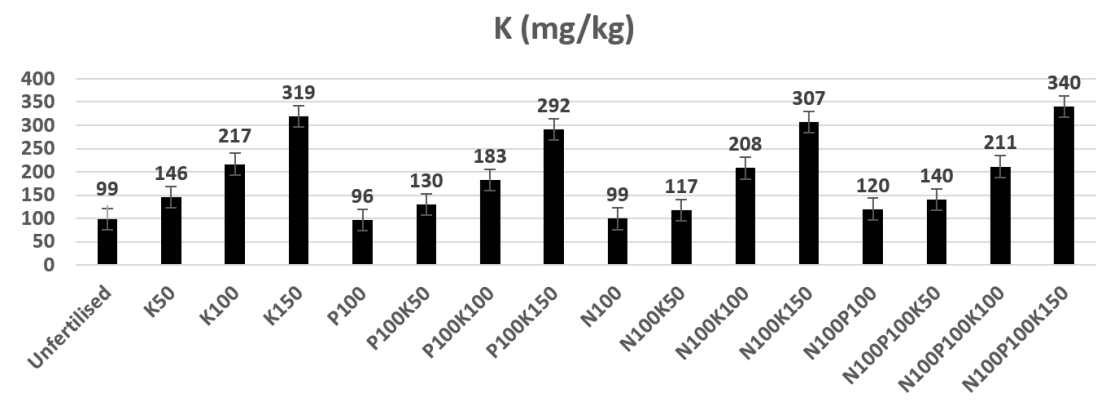

Figure 5. The graphical representation of the influence of long term mineral fertilization (44 years) with NPK on the mobile potassium content from the typical chernozem from Valu lui Traian

Table 1. The Influence of long term fertilization (44 years) with NPK on pH content of soluble salts and some heavy metals from the typical chernozem from Valu lui Traian

\begin{tabular}{ccccccc}
\hline Variant & $\mathrm{pH}$ & $\begin{array}{c}\text { Soluble Solt } \\
(\mathrm{mg} / \mathrm{kg})\end{array}$ & $\mathrm{Cd}(\mathrm{mg} / \mathrm{kg})$ & $\mathrm{Cu}(\mathrm{mg} / \mathrm{kg}) \mathrm{Pb}(\mathrm{mg} / \mathrm{kg}) \mathrm{Zn}(\mathrm{mg} / \mathrm{kg})$ \\
\hline Unfertilized & 7.9 & 66 & 0.40 & 21 & 20 & 83 \\
\hline K50 & 7.9 & 65 & 0.41 & 22 & 20 & 83 \\
\hline K100 & 7.9 & 67 & 0.42 & 22 & 20 & 84 \\
\hline K150 & 7.9 & 66 & 0.42 & 22 & 20 & 84 \\
\hline P100 & 8.0 & 70 & 0.44 & 24 & 20 & 84 \\
\hline P100K50 & 8.0 & 65 & 0.45 & 23 & 20 & 84 \\
\hline P100K100 & 8.0 & 72 & 0.45 & 23 & 20 & 84 \\
\hline N100K150 & 7.9 & 70 & 0.45 & 23 & 20 & 84 \\
\hline N100K50 & 7.9 & 67 & 0.43 & 22 & 20 & 84 \\
\hline N100K100 & 8.0 & 73 & 0.43 & 22 & 20 & 84 \\
\hline N100K150 & 7.9 & 73 & 0.44 & 22 & 20 & 84 \\
\hline N100P100K50 & 8.0 & 71 & 0.45 & 24 & 20 & 84 \\
\hline N100P100K100 & 7.9 & 70 & 0.45 & 23 & 20 & 84 \\
\hline N100P100K150 & 7.9 & 65 & 0.46 & 23 & 21 & 84 \\
\hline
\end{tabular}

with NPK is presented in Tab. 5. It highlights the following:

- The soilcontent in mobile potassium has increased significantly with the applied potassium dose compared to the non-fertilized control;

- On the basis of $\mathrm{P}_{100}$ fertilization, the application of $50 \mathrm{~kg} / \mathrm{ha} \mathrm{K}$ has ensured a distinctly significant increase in the mobile potash in the soil; On the same phosphorus background, application of doses of 100 and $150 \mathrm{~kg} / \mathrm{ha} \mathrm{K}$ led to very significant accumulations of potassium in the typical chernozem; Potassium values increased in the soil in proportion to the applied dose;

- Based on fertilization with $\mathrm{N}_{100^{\prime}}$ only doses of 100 and $150 \mathrm{~kg} / \mathrm{ha}$ of $\mathrm{K}$ have led to very significant increases in potassium in the soil;

- Based on fertilization with $\mathrm{N}_{100} \mathrm{P}_{100}$ all potassium doses $(50,100$ and $150 \mathrm{~kg} / \mathrm{ha}$ ) have led to very significant accumulations of potassium in the soil; these combinations provided the highest levels of potassium in the soil;

- Fertilization with $50 \mathrm{~kg} / \mathrm{ha}$ of potassium has kept the low level of supply of soil potassium, whereas $100 \mathrm{~kg} / \mathrm{ha}$ have led to the „big” supply and $150 \mathrm{~kg} / \mathrm{ha}$ of K have Passed the supply level in the „very high" class.

Madjar (2008) appreciated that soluble potassium in the soil solution is directly accessible to plants, and the amount of potassium in the soil solution varies with applied fertilizer, climate and crop history.

The data presented in Tab. 1 on the influence of long-term fertilization (44 years) on NPK fertilizers on the typical chernozem $\mathrm{pH}$ of Valu's Trajan and its content in soluble salts and some heavy metals revealed the following:

- The pH ranged from 7.9 to 8.0, with no changes observed under the influence of the treatments applied; 
- Soil content in soluble salts did not suffer statistically significant changes following mineral fertilization with NPK;

- Cadmium values varied between 0.40 and 0.47 $\mathrm{mg} / \mathrm{kg}$, not statistically significantly altered by the treatments applied;

- Copper values fluctuated between 21 and 24 $\mathrm{mg} / \mathrm{kg}$, the values not being correlated with the treatments applied; The copper reserves in the upper horizon of the soils in our country (total forms) vary within fairly wide ranges, $3-42$ / $\mathrm{kg}$ (Băjescu and Chiriac, 1984), the values being lower on soils with coarse texture and higher with fine texture.

- Lead values have not statistically significantly changed following applied treatments, ranging from 20 to $21 \mathrm{mg} / \mathrm{kg}$;

- The treatments applied did not significantly alter the total zinc content in the soil, the values remaining at $83-84 \mathrm{mg} / \mathrm{kg}$; The average zinc content in the arable soil layer is $20-100 \mathrm{mg} / \mathrm{kg}$ (Sala, 2011).

Soil reaction is a factor that influences the mobility and accessibility of zinc, with zinc deficiency due to the fact that most of the compounds are insoluble or with minimal solubility at neutral-alkaline $\mathrm{pH}$ (Băjescu and Chiriac, 1984).

\section{Conclusions}

At the time of organizing long-term experiences, the issue of ensuring the NPK requirement was secured. Values of $\mathrm{K}$ were introduced in Valu lui Traian because the level of soil supply in this element was low and could lead to a reduction in yield and production quality.

- Production increased with increasing fertilizer doses; the highest yield (4288 kg/ha) was obtained in fertilized variants with N100K150, where the production level increased by $216 \%$ compared to the non-fertilized control (1987 $\mathrm{kg} / \mathrm{ha}$ );

- Potassium fertilization produced a significant increase in production (37\%) by fertilization with $50 \mathrm{~kg} /$ ha $\mathrm{K}$, a distinctly significant production increase (49\%) at $100 \mathrm{~kg} / \mathrm{ha}$ and a very significant increase in production (153\%), compared to unfertilized variant by application of $150 \mathrm{~kg}$ / ha K; on average on the experimental block, fertilization with potassium yielded a $46 \%$ production increase, or $13.8 \mathrm{~kg}$ of wheat per kg of fertilizer; this is a very high increase, due to the low supply of soil with this element;

- Fertilization with $\mathrm{N}_{100} \mathrm{P}_{100}$ provided a very significant plus of production (204\%) compared to the unfertilized witness; on this fertilizer fund with N100P100, the fertilization with 50 $\mathrm{kg} /$ ha of potassium provided a production increase of $209 \%$, at $100 \mathrm{~kg} /$ ha $\mathrm{K}$, an increase of $211 \%$ and the application of $150 \mathrm{~kg} / \mathrm{ha} \mathrm{K}$, a $207 \%$; on this fertilization fund with $\mathrm{N}_{100} \mathrm{P}_{100}$ potassium has not yet provided significant production surpluses compared to background fertilization; The increase in wheat production per $\mathrm{kg}$ of $\mathrm{K}$ was only $1.3 \mathrm{~kg} / \mathrm{kg}$;

- Following the production increase on the blocks, compared to the unfertilized version, it can be noticed that by K-only fertilization the average production yield was 35\%, on the background of $\mathrm{P}_{100}$ the average growth was $79 \%$, on the background of the $\mathrm{N}_{100}$ average growth Was $103 \%$ and on the background of $\mathrm{N}_{100} \mathrm{P}_{100}$ the average increase was $208 \%$, and the wheat per $\mathrm{kg}$ of $\mathrm{K}$ was $13.8 \mathrm{~kg} / \mathrm{kg}$ in the fertilized block with only $\mathrm{K}, 19 \mathrm{~kg} / \mathrm{kg}$ by applying $\mathrm{K}$ on the background of $\mathrm{P}_{100}$, of $9.4 \mathrm{~kg} / \mathrm{kg}$ in the case of application of K on the background of N100 and of $1.3 \mathrm{~kg} / \mathrm{kg}$ in the case of applying $\mathrm{K}$ on the background of $\mathrm{N}_{100} \mathrm{P}_{100}$;

- It can be concluded that fertilization with potassium is efficient and obligatory for wheat cultivation on the typical chernozem of Valu lui Traian.

- Considering the potassium regime in the soil, to provide plants with this element on poorly supplied soils, the fertilizer doses will exceed the plant need by $50 \%$.

- Various doses of mineral fertilizers with applied NPK did not lead to statistically significant changes in the humus and total nitrogen content of the typical chernozem of Valu Traian.

- Fertilization with $100 \mathrm{~kg} / \mathrm{ha}$ of phosphorus alone or together with doses of $50-150 \mathrm{~kg} / \mathrm{ha}$ of potassium and $\mathrm{N}_{100} \mathrm{P}_{100}$ fertilization along with doses of 50-150 kg / ha of potassium have led to very significant increases in the level of mobile phosphorus in the soil;

- In all variants fertilized with $100 \mathrm{~kg} / \mathrm{ha} P$ the level of soil supply in this element has become „very high”; 
- The soilcontent in mobile potassium hasincreased significantly with the applied potassium dose compared to the non-fertilized control;

- Fertilization with $50 \mathrm{~kg} / \mathrm{ha}$ of potassium has kept the low level of supply of soil potassium, whereas $100 \mathrm{~kg} /$ ha have led to the „big” supply and $150 \mathrm{~kg} / \mathrm{ha}$ of $\mathrm{K}$ have passed the supply level in the „very high" class.

- Long-term fertilization with NPK did not lead to statistically significant changes in $\mathrm{pH}$ and soil content in soluble salts and heavy metals (copper, zinc, lead and cadmium).

\section{References}

1. Băjescu I, Chiriac A, (1984). The distribution of microelements in soils in Romania, Implications in agriculture, Ed Ceres, Bucharest.

2. Borlan Z, Hera C (1984). Agrochemical optimization of the soil-plant system, R.S.R. Academy Publishing House, Bucharest.

3. Borlan Z., Hera C, Dornescu D, Kurtinecz P, Rusu M, Buzdugan I, Tanase G, (1994). Fertility and Soil Fertilization. Ceres Publishing House, Bucharest.
4. Ciobanu G (1999). Influence of organic and mineral fertilizers on the production and quality of wheat and corn. In the Works of the First Symposium of the Plant Culture Section; "Sustainable-Performance Agriculture". Coordinator C. Hera, AGRIS Publishing House - Editor of Agricultural Magazines, Bucharest.

5. Davidescu D, Davidescu V (1979). Potassium in Agriculture, RSR Academy Publishing House, Bucharest.

6. Dorneanu A (2001). The Production and Use of Chemical Fertilizers in the Perspective of the Development of Sustainable Agriculture. In: "Scientific Research and Sustainable Agriculture", Coordinator C. Hera, AGRIS Publishing House.

7. Madjar R (2008). Agrochemistry. Plant and Soil, INVEL Multimedia.

8. Răuţă C, Dumitru M (1986). Fertilizing value of zootechnical waste. In: "Utilization for the vegetal production of sludge and waste water from zootechnical complexes". Co-ordination team: M. Dumitru, Vl. Ionescu Sisești, St. Nastea, C.Răuţă, Agricultural Propaganda Editor.

9. Sala F. (2011). Agrochemistry, Publishing house Eurobit, Timişoara;

10. Vintila I, Borlan Z, Răuţă C, Daniliuc D, Ţigănaș L (1984). The agrochemical situation of soils in Romania. Present and future. Ceres Publishing House. 